\title{
Atlas of advanced electrocardiogram interpretation (Editor: Adrian Baranchuk, MD, FACC, FRCPC)
}

\author{
Sergio Dubner \\ Clinica y Maternidad Suizo Argentina and De Los Arcos Sanatorio, Buenos Aires, Argentina
}

The electrocardiogram (ECG) continues to be one of the most frequently used diagnostic tools in modern medicine.

Whilst medical technology and imaging continues to evolve to more sophisticated technologies, the simple and inexpensive ECG remains as an invaluable tool not only to establish a proper diagnosis but also to determine prognosis and to guide medical actions.

Its value is of utmost importance in acute coronary syndromes, cardiac arrhythmias, conduction disorders, selection of candidates to cardiac devices, identification of hereditary arrhythmic disorders, etc.

Surface ECG interpretation skill is taught in all medical schools around the world, in all nursing schools, and in all medical residencies.

Several books were published in the past to explain and teach the electricity of the heart, using different teaching modalities, pursuing different goals, and targeting different audiences.
However, an "Atlas of advanced electrocardiogram interpretation" [1] showing common and uncommon ECG patterns was lacking. An easily accessible and modern interactive tool that could be used both to help recognize patterns and also as teaching material was not available on the market.

This is why I applaud the initiative of Dr Adrian Baranchuk, an invasive electrophysiologist from Queen's University, Kingston, Ontario, Canada of publishing what I consider an invaluable digital book, which will contribute to the medicine learners' understanding of advanced ECGs and their familiarity with the recognition of patterns that are not so common. Some of the examples published in the book were previously published in "Cardiology Journal" [2-4], but the format of the Atlas allows to understand these patterns better.

The Atlas [1] (Figs. 1, 2) is a digital book composed of 12 chapters and 100 cases. What is different in this Atlas while compared to other books?

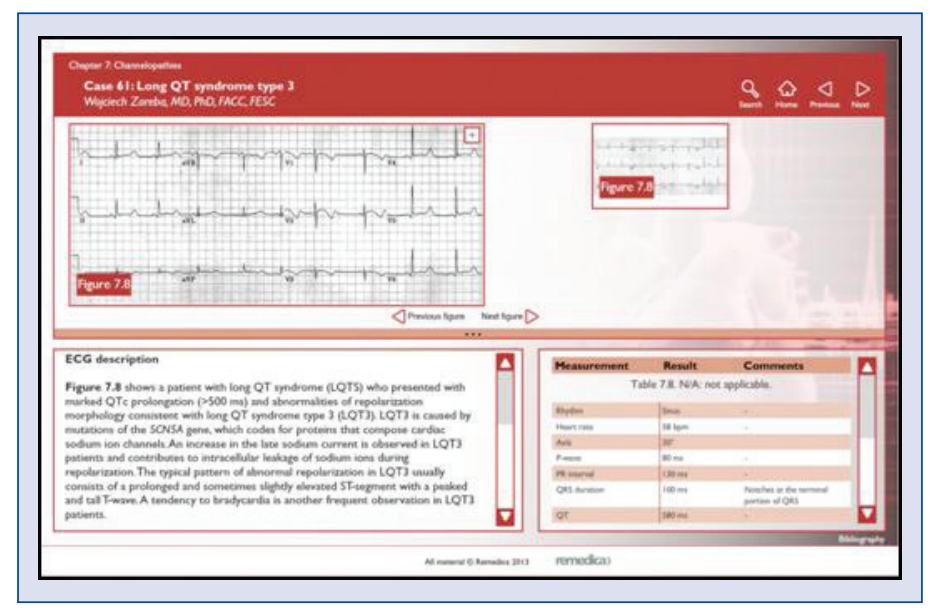

Figure 1. Atlas' example. Long QT type 3 by W. Zareba, former Editor-in-Chief, "Cardiology Journal", current Editor-in-Chief, "Annals of Noninvasive Electrocardiology".

Address for correspondence: Sergio J. Dubner, MD, FACC, Editor-in-Chief Cardiology Journal, Director Arrhythmias and Electrophysiology Service, Clinica y Maternidad Suizo Argentina and De Los Arcos Sanatorio, Arenales 2463 - 3 A, 1124 Buenos Aires, Argentina, tel: (+5411) 4827 3654, e-mail: sdubner@cardiologyjournal.org 


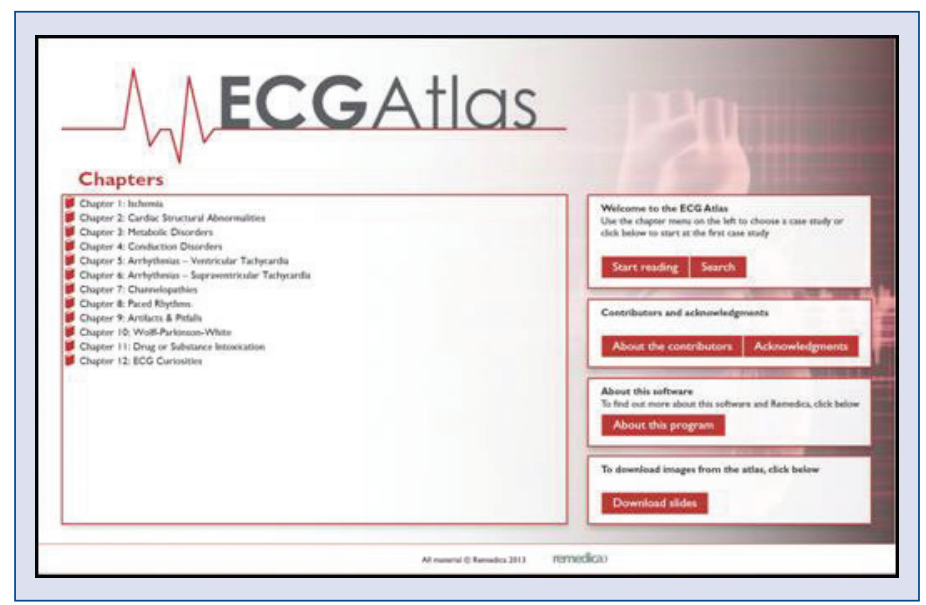

Figure 2. Atlas' layout.

1. Its digital interactive format helps the reader to learn and have fun at the same time. Each case brings the ECG description, points to ponder upon (each author inserts the ECG into a clinical context), a table with all measurements, and recommended bibliography for expanding knowledge.

2. Each case is analyzed by an expert in the topic: What could be better than to read Dr Pedro Brugada explaining the Brugada ECG pattern himself? Or to have Dr Belhassen describing Belahassen's ventricular tachycardia?

3. Each image can be downloaded in PPT format in order to be used for teaching purposes. This makes "The Queen's Atlas of ECGs" a perfect tool for those of us with teaching responsibilities in our centers and units.

The chapters on pacing rhythms and on channelopathies deserve separate comments. These two topics of increasing interest in the medical field became more relevant in the last few years. Most internists and cardiologists will be exposed to these ECGs and gaining familiarity with these patterns is of utmost importance.

I would like to invite you to navigate this Atlas, to learn from ECG Masters from around the globe (several Canadian colleagues like Paul Dorian, Martin Green or Andrew Krahn) from the USA (S. Serge Barold and Paul Levine teaching pacing rhythms is priceless!; Kenneth Ellenbogen, and many others); from Europe (Jeronimo Farre, Silvia Priori, Gregory Lip); from South America (Andres
Ricardo Perez-Riera and so many others); from Israel, Australia, Japan...

At the same time, while we are moving from case to case, we are traveling from continent to continent to gain knowledge from all of them...

The two forewords preceding the book from Dr Pedro Brugada (Belgium) and Dr Antoni Bayes de Luna (Spain) are vivid examples of what this young electrophysiologist from Queen's is capable to do: to bring the Masters altogether, to bring the knowledge altogether; and to share with the rest of us his ability to implement knowledge translation in a field where communication is the key in helping medical decision making.

I congratulate the Editor of the Atlas for bringing us this amazing material that I believe will be a part of the mandatory learning material for all those that are willing to learn the fascinating world of ECGs.

\section{Conflict of interest: none declared}

\section{References}

1. Baranchuk A. Atlas of advanced electrocardiogram interpretation. Baranchuk A ed. REMEDICA, London, UK 2013 (www.ECGAtlas.com).

2. Baranchuk A, Somani R, Simpson CS, Michael KA, Redfearn DP. Ablation of a left lateral accessory pathway in a patient with dextroposition of the heart. Cardiol J, 2012; 19: 439-440.

3. Pérez Riera AR, Paixão-Almeida A, Barbosa-Barros R et al. Congenital short QT syndrome: Landmarks of the newest arrhythmogenic cardiac channelopathy. Cardiol J, 2013; 20: 464-471.

4. Ramineni R, Bheemarasetti MK, Baranchuk A et al. Management of arrhythmias in heart failure. What a practicing physician should know in the current times. Cardiol J, 2012; 19: 567-577. 